\title{
Audit of defibrillators at an urban public sector hospital
}

\author{
S'fisosikayise Madi, ${ }^{1,2}$ Feroza Motara, ${ }^{1,2}$ Callistus Enyuma, ${ }^{1,3}$ Abdullah Ebrahim Laher ${ }^{1,2}$
}

Department of Emergency Medicine, Faculty of Health Sciences, University of the Witwatersrand, Johannesburg, South Africa

${ }^{2}$ Department of Emergency Medicine, Charlotte Maxeke Johannesburg Academic Hospital, Johannesburg, South Africa

${ }^{3}$ Department of Paediatrics, Faculty of Medicine, University of Calabar /Teaching Hospital, Calabar, Nigeria

\section{Correspondence to} Dr Abdullah Ebrahim Laher, Department of Emergency Medicine, Charlotte Maxeke Johannesburg Academic Hospital, Johannesburg 2193, South Africa; abdullahlaher@ msn.com

Received 11 May 2018 Revised 16 July 2018 Accepted 20 July 2018

\section{Check for updates}

(c) Author(s) (or their employer(s)) 2018. No commercial re-use. See rights and permissions. Published by BMJ.

To cite: Madi S, Motara F, Enyuma $\mathrm{C}$, et al. Heart Asia 2018:10:e011065. doi:10.1136/

heartasia-2018-011065

\begin{abstract}
Introduction Life-threatening emergencies are not limited to the emergency department. Any delay in intervention during an emergency often culminates into a poor outcome. Early electrical defibrillation is one of the most important interventions in patients with cardiac arrest. This study aimed to conduct a clinical audit of defibrillator devices at an urban public sector hospital in Johannesburg.
\end{abstract}

Methods All defibrillator devices within various areas of the hospital were assessed. Device characteristics were recorded into a data collection sheet and subjected to further analysis.

Results This study assessed 112 out of 123 areas in the hospital with a total of 143 defibrillators comprising 139(97.2\%) manual external defibrillators (MED) and four(2.8\%) automated external defibrillators (AED). MEDs were located in the general wards $(n=52,37.4 \%)$, theatre complex $(n=25,17.9 \%)$, high dependency areas $(n=27,19.4 \%)$ and non-sleepover areas $(n=35,25.2 \%)$. Daily checklist books were available for 101 (72.7\%) MEDs, 26 (18.7\%) had at least once daily documented checks over a 5-day period while $57(41.0 \%)$ had been serviced in the last 12 months. Seven MEDs (4.9\%) and one AED (0.7\%) had critical problems.

Conclusion Compliance with regard to the availability of defibrillator checklist books, conducting and recording of daily defibrillator checks, timely service maintenance of defibrillators and identification of critical device problems was suboptimal in this study. There is a need for ongoing training of hospital staff as well as the establishment of systems to prevent potential adverse consequences due to device failure.

\section{INTRODUCTION}

Presentations of life-threatening emergencies are not limited to the emergency department (ED) but may occur in any location within the hospital including admission wards, operating theatres, the radiology department, the cafeteria as well as in the elevator. As such, life-saving equipment should be readily available and in good working condition, ${ }^{1}$ as delays secondary to equipment failure are often associated with poor outcomes. ${ }^{23}$

Medical device failures may be classified into five broad categories that include device factors, external factors, support system failures, tampering or sabotage, and user errors. Device malfunction, lack of training, unreliability of power supply, improper storage, failure to perform a preuse inspection and poor maintenance are some of the more common causes of device failure under these categories. ${ }^{4}$ The design and user interface of the device also play a pivotal role in reducing operator errors. ${ }^{5}$
Equipment failure has been shown to be responsible for delays in instituting cardiopulmonary resuscitation in $18 \%$ of cases. ${ }^{2}$ In 1989 , the Defibrillator Working Group concluded that the frequency of defibrillator device failure was unacceptably high, with operator errors and inadequate attention to device care, lack of daily device checks and timely maintenance being the chief reasons. These deficiencies were attributed to poor operator training and a lack of instituting adequate quality control measures. ${ }^{6}$

Despite the availability of local and international guidelines and checklist, ${ }^{78}$ there is a paucity of local data pertaining to the current state of defibrillators in clinical care settings. To determine this and to assess the degree of compliance with current standards, we conducted an audit of defibrillator devices in clinical use at an urban public sector hospital.

\section{METHODS}

This prospective study comprised a clinical audit of all defibrillators at a large urban public sector hospital in Johannesburg. Johannesburg has 10 public sector hospitals and is one of the 50 largest urban cities in the world with a cosmopolitan population of approximately 1 million people. ${ }^{9}$ This study was conducted at a 1068-bed tertiarylevel care hospital that services a major portion of the Johannesburg inner city region as well as surrounding suburban areas. As per figures from the hospital statistics department, approximately 46000 patients are admitted to the hospital annually. The hospital also has 26 outpatient department (OPD) areas that together run approximately 2600 OPD clinics per annum with approximately 104000 patients attending these clinics every year. Since the hospital does not have a dedicated cardiac arrest team or committee, all cardiac arrest scenarios are informally managed by on-shift clinical staff stationed in each area of the hospital.

The study assessed all areas within the hospital which were categorised as follows: (1) general wards (medical, surgical, paediatric, obstetrics and gynaecology); (2) operating theatre complex (operating rooms, perioperative areas); (3) high dependency areas (intensive care units (ICU), EDs); and (4) non-sleepover areas (OPDs, allied health departments, radiology areas). Devices that were not in current clinical use and stored at the hospital's central equipment storage were excluded from the study. These devices were either declared non-functional, out of order, awaiting repair or condemned by the hospital equipment engineer.

Data were collected between 1 and 30 May 2016 and conducted by the primary investigator who was 
not blinded to the study aims and objectives. The exact location of defibrillator devices in the various areas was established with the aid of the area unit manager or charge sister. To eliminate notification bias, data collection was unscheduled. Collected data included the location of the device, the number and types of devices present at each location, device brand name and model, presence of a daily checklist book, regularity of daily morning and evening checks conducted over the last 5 days, whether a maintenance service was conducted in the preceding 12 months and compliance of the device with the Emergency Medicine Society of South Africa (EMSSA) checklist. Components of the EMSSA defibrillator checklist are listed in column 1 of table 2.

Data were electronically captured into a specifically designed data collection sheet that was created in REDCap, ${ }^{10}$ which uses a MySQL database via a secure web interface. Data were analysed using the Statistical Package for the Social Sciences (SPSS), V.24.0 (IBM). All data were categorical in nature and tabulated as frequencies and proportions.

\section{RESULTS}

One-hundred and twenty-three areas that included 50 general wards (18 medical, 15 surgical, 9 paediatric, 8 obstetrics and gynaecology), 14 high dependency areas (11 ICUs, 3 ED units), 39 non-sleepover areas (26 OPDs, 4 allied health departments, 9 radiology areas) and 20 theatre complex areas (18 theatre rooms, 2 perioperative waiting areas) were identified. A total of 11 areas (8.9\%) were excluded. Ten of these areas did not have a defibrillator (two surgical wards, three paediatric wards, five radiology areas) whereas consent for study participation could not be obtained from one area (an allied health department). Therefore, 112 areas (91.1\%) were included in the final sample for analysis.

A total of 143 defibrillators were identified in the 112 areas that were included in the study. This comprised 139 (97.2\%) manual external defibrillators (MED) and four (2.8\%) automated external defibrillators (AED). More than one device was identified in $20(21.5 \%)$ areas. Devices were available in all of the high dependency $(n=14)$ and theatre complex areas $(n=20)$, whereas devices were available in only $45(90.0 \%)$ and $33(86.8 \%)$ of the general wards and non-sleepover areas, respectively.

The 139 MEDs belonged to 11 different brand and model types. Majority of the MEDs $(n=101,72.7 \%)$ were of a single brand and model type (Philips HeartStart XL, Koninklijke Philips, Amsterdam, Netherlands). The brand and model types of the remaining 38 MEDs were as follows: 13 (9.4\%) Nihon Kohden TEC 5521 (Nihon Kohden, Tokyo, Japan), 11 (7.9\%) Zoll M series (Zoll Medical, Massachusetts, USA), 3 (2.2\%) Welch Allyn PIC30's (Welch Allyn, New York, USA), 2 (1.4\%) Hewlett Packard 43 120a (Hewlett-Packard, California, USA), 2 (1.4\%) GE Medical Systems CardioServ (General Electric Healthcare, Massachusetts, USA), 2 (1.4\%) Medical Research Laboratory Porta Pak/90A (Medical Research Laboratories, Cincinnati, USA), 2 (1.4\%) Medical System Paramedic CU-ER5 (CU Medical Systems, Gyeonggi-do, Korea), $1(0.7 \%)$ Mindray BeneHeart D6 (Mindray Medical International, Shenzhen, China), 1 (0.7\%) Lifepak 9 Physio Control (Physio-Control, Redmond, USA) and 1 (0.7\%) Life Gain (CU Medical Systems).

Brand and model types of the four AEDs in the hospital comprised one (25\%) each of Welch Allyn AED 20 (Welch Allyn), CU Medical Systems Paramedic (CU Medical Systems), GE Responder AED and GE Responder AED Pro (General Electric Healthcare).
Based on the number of subareas in the four major areas identified, there were proportionately more MEDs in the high dependency areas $(1.93: 1)$, followed by the operating theatre complex (1.25:1), general wards $(1.04: 1)$ and the non-sleepover areas (0.92:1). Of the four AEDs in the hospital, two (50\%) were located in the OPD, while one (25\%) device each was located in a surgical ward and the radiology department.

One-hundred and one (72.7\%) MEDs had a daily checklist book. Almost all MEDs in the high dependency wards $(n=26$, 96.3\%) had a checklist book, whereas less than half of those located in the non-sleepover areas $(42.9 \%, \mathrm{n}=15)$ had a checklist book. Over the 5 -day period prior to data collection, only 26 (18.7\%) MEDs had $\geq 1$ documented check per day.

Fifty-seven (41.0\%) MEDs had a service maintenance stamp that was dated within the last 12 months. Of these, 49 were of the Philips HeartStart XL make (48.5\% of the 101 Philips devices in the hospital) and eight were of the other brands listed above (21.1\% of the 38 non-Philips devices in the hospital). Table 1 describes details of manual defibrillators located in various areas across the hospital with regard to the overall distribution, availability of checklist books and performance of a maintenance service within the last 12 months.

Table 2 comprehensively describes the degree of compliance of MEDs in the four major areas with EMSSA defibrillator checklist guidelines. None of the devices had met all the requirements specified in the EMSSA checklist guidelines. Assessing the devices using overall averages, the non-sleepover areas achieved the highest overall average $(82.1 \%)$ whereas the general wards had the lowest average (70.6\%).

Table 3 describes the seven (5\%) MEDs that were assessed as having critical problems. These devices were located in the medical wards $(n=3)$, ICUs $(n=2)$, surgical ward $(n=1)$ and the OPD $(n=1)$. Power supply and battery malfunction were the chief critical problems. It was noted that two of the MEDs were able to discharge only when plugged into a live outlet. Included in the seven was a device that had been condemned by the operational manager in the unit. This device was included in the study as it was placed on a ward resuscitation trolley. There were $12(8.6 \%)$ devices in total that were not plugged into a live wall socket outlet. Three of these devices had failed the initial discharge test as the battery had failed. After charging, the devices were able to discharge as per manufactures' instruction.

With regard to the four AEDs in the hospital, two (50\%) were serviced within the last 12 months. Both were located in the OPD areas. None of the four AEDs had a checklist book and none of the units had two sealed AED pad sets (three had only one pad, with the fourth having no pads at all). There was one AED with a critical problem which was power related.

\section{DISCUSSION}

The incidence of adult in-hospital cardiac arrest in the UK has been reported as 1.6 per 1000 hospital admissions. ${ }^{11}$ In contrast, a Ugandan study reported an exceptionally high rate of 190 cardiac arrest episodes among 8131 hospital admissions (23.4 per 1000). ${ }^{12}$ Although the incidence of in-hospital cardiac arrest is not known in South Africa, the incidence of out-of-hospital cardiac arrest has been reported as 6.4 per 100000 population. ${ }^{13}$ There are no available data with regard to the incidence of in-hospital cardiac arrest at the study site hospital.

Although there were a substantial number of defibrillator devices available for clinical use at the facility $(n=143)$, there are no guidelines to suggest how many devices are expected within a healthcare facility. Almost all devices at the facility (97.2\%) 
Table 1 Description of overall distribution, availability of checklist books and performance of a maintenance service within the last 12 months of manual defibrillators located in various areas across the hospital

\begin{tabular}{|lccccc}
\hline $\begin{array}{l}\text { Areas assessed for the } \\
\text { presence of a MED }\end{array}$ & $\begin{array}{l}\text { Total number of } \\
\text { MEDs, } \mathbf{n}(\%)\end{array}$ & $\begin{array}{l}\text { Areas with one or } \\
\text { more MEDs, } \mathbf{n}(\%)\end{array}$ & $\begin{array}{l}\text { MEDs with a daily } \\
\text { checklist book, } \mathbf{n}(\%)\end{array}$ & $\begin{array}{l}\text { Checklist books with } \geq 1 \\
\text { documented check per day } \\
\text { over the previous } 5 \text { days, } \mathbf{n}(\%)\end{array}$ & $\begin{array}{l}\text { MEDs with a service } \\
\text { maintenance stamp dated within } \\
\text { the last 12 months, } \mathbf{n}(\%)\end{array}$ \\
\hline General wards $(n=50)$ & $52(37.4)$ & $45(90.0)$ & $43(82.6)$ & $14(26.9)$ & $19(36.5)$ \\
\hline Medical $(n=18)$ & $21(40.4)$ & $18(100.0)$ & $19(90.5)$ & $8(38.1)$ & $5(23.8)$ \\
\hline Surgical $(n=15)$ & $15(28.8)$ & $13(86.6)$ & $13(86.7)$ & $5(33.3)$ & $7(46.7)$ \\
\hline Paediatric $(n=9)$ & $7(13.5)$ & $6(66.6)$ & $6(85.7)$ & $0(0.0)$ & $3(42.8)$ \\
\hline O\&G $(n=8)$ & $9(19.3)$ & $8(100.0)$ & $5(55.6)$ & $1(11.1)$ & $4(44.4)$ \\
\hline Operating theatre complex $(n=20)$ & $25(17.9)$ & $20(100.0)$ & $17(68.0)$ & $5(20.0)$ & $10(40.0)$ \\
\hline Operating rooms $(n=18)$ & $23(92.0)$ & $18(100.0)$ & $16(69.5)$ & $5(21.7)$ & $10(43.4)$ \\
\hline Perioperative areas $(n=2)$ & $2(8.0)$ & $2(100.0)$ & $1(50.0)$ & $0(0.0)$ & $0(0.0)$ \\
\hline High dependency areas $(n=14)$ & $27(19.4)$ & $14(100.0)$ & $26(96.3)$ & $4(14.8)$ & $17(63.0)$ \\
\hline ICUs $(n=11)$ & $19(70.4)$ & $11(100.0)$ & $18(94.7)$ & $3(15.8)$ & $13(68.4)$ \\
\hline EDs $(n=3)$ & $8(29.6)$ & $3(100.0)$ & $8(100.0)$ & $1(12.5)$ & $4(50.0)$ \\
\hline Non-sleepover areas $(n=38)$ & $35(25.2)$ & $33(86.8)$ & $15(42.9)$ & $3(8.6)$ & $11(31.4)$ \\
\hline OPD areas $(n=26)$ & $27(77.1)$ & $26(100.0)$ & $14(51.9)$ & $3(11.1)$ & $9(33.3)$ \\
\hline Allied health areas $(n=3)$ & $3(8.6)$ & $3(100.0)$ & $0(0.0)$ & $0(0.0)$ & $0(0.0)$ \\
\hline Radiology areas $(n=9)$ & $5(14.3)$ & $4(44.4)$ & $1(20.0)$ & $0(0.0)$ & $2(40.0)$ \\
\hline Total & 139 & $112(91.8)$ & $101(72.7)$ & $26(18.7)$ & $57(41.0)$ \\
\hline
\end{tabular}

ED, emergency department (adult medical and surgical, adult trauma, paediatric); ICU, intensive care unit (adult multidisciplinary ICU, adult multidisciplinary high care, trauma ICU, neurosurgical ICU, cardiology ICU, cardiothoracic ICU, neonatal ICU, neonatal high care, paediatric ICU, obstetrics high care); 0\&G, obstetrics and gynaecology; OPD, outpatient department; MED, manual external defibrillator.

comprised MEDs. This may be understandable as operators in a healthcare setting are generally professionals who are expected to possess the knowledge and skill on the effective use of a MED.

Majority of the MEDs in the hospital (72.7\%) were of a single brand and model type. A potential benefit of a single device type across a facility is that users may be better acquainted with the use of the device. This then may lead to fewer errors during resuscitations within the hospital. Other potential benefit of a single brand and model type relates to the cost saving associated with the annual maintenance and servicing of a large number of devices from a single manufacturer as well as the ease of arranging these maintenance services. This is supported by the fact that in this study, proportionately more devices of the Philips brand were serviced as compared with devices that were of non-Philips brand (48.5\% vs $21.1 \%)$. However, there is a paucity of evidence in the literature to clearly demonstrate the benefits of a single device brand and model. Hence, this is a potential area of further study.

Due to the nature and acuity of patients seen in the high dependency areas (ICU and ED), it is understandable that these areas have proportionately more MEDs (1.93:1). Since cardiac events requiring the use of a defibrillator device are more common in perioperative patients, the operating theatre complex is also a high-risk area. ${ }^{14}$

It is also commendable that there was on average more than one functional MED (1.28:1) per operating room. Also the relatively smaller ratio of devices in the paediatric wards $(0.78: 1)$ and radiology areas $(0.56: 1)$ may be acceptable as shockable cardiac rhythms are less common in paediatric patients, ${ }^{15} 16$ while cardiac arrest is rare in the radiology department. Hope et al reported an incidence rate of cardiac arrest in the radiology department of $0.002 \%$ in their study. ${ }^{17}$ There is however no literature to suggest that having more than one defibrillator device in an area or ward is associated with improved patient outcomes.

Every defibrillator is expected to have a checklist book for documentation of daily device checks. ${ }^{18}$ This serves as a means of quality assurance to mitigate errors and device failures which may occur during an emergency. The American Heart Association recommends that defibrillators be maintained in a state of readiness; hence checklists are crucial in identifying device deficiencies. $^{8}$

As per institutional policy at the study site, it is the responsibility of the nursing shift leader to ensure that daily defibrillator checks are completed and documented. It is of concern that more than a quarter of MEDs (27.3\%) and none of the four AEDs in the hospital had a checklist book. Possible reasons why checklist books were not present with all devices include a lack of understanding of its importance, redundant devices in less emergent areas, lack of ongoing training and entrusting junior or inexperienced staff with the task. The overall prevalence of a checklist book was however much higher in our study compared with the findings by Louw et al, who, in a questionnaire-based study that surveyed 27 EDs at district, regional and central hospitals in the Western Cape province of South Africa, reported that 26\% of defibrillator devices had a dedicated device check logbook. ${ }^{19}$ Both findings do however highlight the challenges faced with regard to device checks being conducted at healthcare facilities in South Africa.

Of greater concern is that only $18.7 \%$ of all MEDs $(25.7 \%$ of MEDs with a checklist book) were subject to at least one documented check per day over the previous 5 days prior to data collection. In the study by Louw and colleagues, 67\% of EDs conducted testing but only $52 \%$ of these were conducted daily. ${ }^{19}$ Hence, the presence of the checklist book does not necessarily mean that daily checks are taking place, thereby emphasising the need for further education and surveillance.

The use of defibrillator checklists ensures a comprehensive understanding of the device function and operation ${ }^{1}$ and is also crucial in maintaining optimal defibrillator function. ${ }^{20}$ None of the devices in this study were able to adhere to all the parameters described in the EMSSA defibrillator checklist guidelines. Of note, a significant proportion of the low percentages were in the supplies and consumables category and included the availability of monitoring electrodes, alcohol wipes, hand towels, 
Table 2 Compliance of manual defibrillators in the four major clinical areas with the Emergency Medicine Society of South Africa (EMSSA) defibrillator checklist guidelines

\begin{tabular}{|c|c|c|c|c|c|}
\hline Items investigated & $\begin{array}{l}\text { General wards } \\
(n=52)\end{array}$ & $\begin{array}{l}\text { Theatre complex } \\
(n=25)\end{array}$ & $\begin{array}{l}\text { High dependency } \\
\text { areas }(n=27)\end{array}$ & $\begin{array}{l}\text { Non-sleepover areas } \\
(n=35)\end{array}$ & $\begin{array}{l}\text { Total } \\
(n=139)\end{array}$ \\
\hline \multicolumn{6}{|l|}{ 1. Defibrillator unit } \\
\hline Clean/no spills/clear of objects on top casing intact & $47(90.4 \%)$ & $25(100.0 \%)$ & $27(100.0 \%)$ & $35(100.0 \%)$ & $134(96.4 \%)$ \\
\hline \multicolumn{6}{|l|}{ 2. Paddles } \\
\hline Clean/not pitted & $38(73.1 \%)$ & $18(72.0 \%)$ & $26(96.3 \%)$ & $32(91.4 \%)$ & $114(82.0 \%)$ \\
\hline Easily releases from housing & $51(98.1 \%)$ & $25(100.0 \%)$ & $26(96.3 \%)$ & $35(100.0 \%)$ & $137(98.6 \%)$ \\
\hline Connectors engage securely and are not damaged & $49(94.2 \%)$ & $22(88.0 \%)$ & $27(100.0 \%)$ & $35(100.0 \%)$ & $133(95.7 \%)$ \\
\hline \multicolumn{6}{|l|}{ 4. Supplies } \\
\hline Monitoring electrodes & $29(55.8 \%)$ & $20(80.0 \%)$ & $25(92.7 \%)$ & $33(94.3 \%)$ & $107(76.9 \%)$ \\
\hline Alcohol wipes & $6(11.5 \%)$ & $10(40.0 \%)$ & $8(29.6 \%)$ & $17(48.6 \%)$ & $41(29.5 \%)$ \\
\hline Hand towel & $3(5.8 \%)$ & $6(24.0 \%)$ & $5(18.5 \%)$ & $14(40.0 \%)$ & $28(20.1 \%)$ \\
\hline \multicolumn{6}{|l|}{ 5. Power supply } \\
\hline Plugged into live outlet to maintain battery & $47(90.4 \%)$ & $22(88.0 \%)$ & $24(88.6 \%)$ & $34(97.1 \%)$ & $127(91.3 \%)$ \\
\hline Test on battery power, then reconnects to line power & $48(92.3 \%)$ & $24(96.0 \%)$ & $26(96.3 \%)$ & $35(100.0 \%)$ & $83(95.7 \%)$ \\
\hline \multicolumn{6}{|l|}{ 6. Indicators/ECG display } \\
\hline Power on display & $50(96.2 \%)$ & $25(100.0 \%)$ & $27(100.0 \%)$ & $34(97.1 \%)$ & $136(97.8 \%)$ \\
\hline Self-test passed & $46(88.5 \%)$ & $22(88.0 \%)$ & $26(96.3 \%)$ & $35(100.0 \%)$ & $129(92.8 \%)$ \\
\hline Monitor display functional & $52(100.0 \%)$ & $25(100.0 \%)$ & $27(100.0 \%)$ & $35(100.0 \%)$ & $139(100.0 \%)$ \\
\hline Battery charging: 'low battery' light off & $42(80.8 \%)$ & $21(84.0 \%)$ & $19(70.3 \%)$ & $34(97.1 \%)$ & $116(83.4 \%)$ \\
\hline Correct time displayed & $46(88.5 \%)$ & $19(76.0 \%)$ & $22(81.5 \%)$ & $30(85.7 \%)$ & $117(84.2 \%)$ \\
\hline \multicolumn{6}{|l|}{ 7. ECG recorder } \\
\hline Overall compliance* & $(70.6 \%)$ & $(75.4 \%)$ & $(75.5 \%)$ & $(82.1 \%)$ & $(75.9 \%)$ \\
\hline
\end{tabular}

${ }^{*}$ Calculated as an average of the scores of all 26 items listed in column 1.

$A C$, alternating current.

scissors, razors, spare ECG paper and conductive gel. Failure to use conductive gel places the patient at high risk of burn injury to the skin. ${ }^{21}$ Due to cost constraints, none of the defibrillator devices at the study site had self-adhesive pads. Surprisingly, the non-sleepover areas performed the best with regard to overall compliance. The availability of supplies was on average also better than the other areas in the hospital. A possible reason for this is that the devices and consumables are not used frequently in these areas.

As per manufacturer's recommendations, defibrillator devices should be subjected to a maintenance service by the manufacturer at least annually (personal communication with device manufacturers). In the USA, the Defibrillator Working Group survey had reported that $20 \%$ of devices in hospitals and EDs

Table 3 Description of the manual defibrillators with critical problems

\begin{tabular}{lllll}
\hline Location & Device brand name and model & $\begin{array}{l}\text { Maintenance service performed } \\
\text { in the last 12 months }\end{array}$ & $\begin{array}{l}\text { Presence of daily } \\
\text { checklist book }\end{array}$ & Critical problems \\
\hline Ward (medical) & Philips HeartStart XL & Yes & Yes & Battery not functional \\
\hline Ward (medical) & Hewlett Packard 43 120a & No & No & Did not charge and deliver shock \\
\hline Ward (medical) & Hewlett Packard 43 120a & No & No & Battery and power supply \\
\hline Ward (intensive care unit) & Philips HeartStart XL & Yes & Yes & Did not charge and deliver shock \\
Ward (intensive care unit) & Philips HeartStart XL & Yes & No & Battery and power supply \\
\hline Ward (surgical) & Philips HeartStart XL & No & No & Battery and power supply \\
\hline Outpatient department & Lifepak 9 Physio Control & No & & Battery not functional \\
\hline
\end{tabular}


had not been subject to their scheduled annual maintenance. ${ }^{6}$ More than double (41\%) the number of MEDs in this study did not have a service maintenance stamp that was dated within the last 12 months. However, other possible reasons for the lack of a current service maintenance stamp include: devices were newly acquired and not due for maintenance; the maintenance stamp had been removed or fallen off; or devices were not previously serviced. Likely reasons for the devices not being serviced timeously include budgetary constraints or failure of the area manager to identify and report devices that were due for a maintenance service. Since a higher proportion of devices in critical areas (high dependency areas and operating theatre complex) had a maintenance stamp than those in the general wards and non-sleepover areas, the latter areas therefore require more training, support and encouragement in this regard.

Battery-related device failure accounted for five out of the seven MEDs with critical problems. Comparatively, the Defibrillator Working Group reported an incidence of $25 \% .{ }^{6}$ However, battery failures from the Defibrillator Working Group survey were in devices that had already failed during use, whereas we investigated the devices while not in use. There were unfortunately no other recent studies with a comparable study design to compare our results.

The study had limitations in that it was a single-centre study conducted at a public sector hospital in a major metropolitan city. Hence, findings may not represent other geographic parts of South Africa, let alone private facilities. Also, it is possible that some defibrillators may have been omitted as the facility did not possess a registry of devices in the hospital. Furthermore, our study did not evaluate whether daily device checks were being conducted correctly or how frequently were devices being used. Hence, we were unable to describe any association between the frequency of use, device checks and maintenance carried out. Despite these limitations, this study is nevertheless of value to clinicians, managers and stakeholders in varying clinical care settings as the study highlights potential areas of interventions in preventing defibrillator device failure.

Recommendations with regard to strategies that may be considered to ensure optimal function of defibrillators and other critical hospital equipment include: (1) establishment of a dedicated equipment surveillance team with representation of all

\section{Key questions}

What is already known about this subject?

- Defibrillators are central in the management of life threatening cardiac abnormalities

- Life-saving equipment such as defibrillators should be readily available and in good working condition

- Delays secondary to equipment failure is often associated with poor outcomes

What does this study add?

- There is a need for ongoing training of staff with regards to the proper use, completion of daily checklist, procuring of consumables and the routine maintenance of defibrillators in the hospital

\section{How might this impact on clinical practice?}

- It is hoped that results of this study will create awareness and encourage managers, technical staff as well as end-users to implement strategies that will ensure the optimal function of defibrillators across the hospital relevant stakeholders including the end users, technical staff as well as hospital management; (2) updating of device inventories; (3) conducting of regular equipment checks and quality audits; (4) scheduling service maintenance of all defibrillators within the facility at the same time every year; (5) establishing an adverse medical device events database; (6) education and training of staff including end users; and (7) establishing an open feedback strategy. 223

\section{CONCLUSION}

Compliance with regard to the availability of defibrillator checklist books, conducting and recording of daily defibrillator checks, timely service maintenance of defibrillators and identification of critical device problems was suboptimal in this study. There is a need for ongoing training of hospital staff as well as the establishment of systems to prevent potential adverse consequences resulting from device failure.

Contributors SM: guarantor of the manuscript and responsible for the integrity of the data and the accuracy of data analysis, data collection, statistical analysis and interpretation of data; drafting, writing, review and incorporating coauthor's feedback, revision, and approval of the submission. FM: contributed to the study concept; interpretation of the data; review, revision and approval of the manuscript. CE: interpretation of the data; review, revision and approval of the manuscript. AEL: contributed to the study concept and design, statistical analysis and interpretation of data, the drafting and writing, review and incorporating coauthor's feedback, revision and final approval of the manuscript, corresponding author.

Funding The authors have not declared a specific grant for this research from any funding agency in the public, commercial or not-for-profit sectors.

Competing interests None declared.

Patient consent Not required.

Ethics approval Ethical clearance was obtained from the Human Research Ethics Committee (medical) of the University of the Witwatersrand (clearance certificate number M160210) prior to commencement of data collection.

Provenance and peer review Not commissioned; externally peer reviewed.

\section{REFERENCES}

1 White RD. Maintenance of defibrillators in a state of readiness. Ann Emerg Med 1993;22(2 Pt 2):302-6.

2 King D, Davies KN, Cope CS, et al. Survey of cardiac arrests and cardiac arrest trolleys in a district general hospital. Br J Clin Pract 1994;48:248-50.

3 Valenzuela TD, Roe DJ, Cretin S, et al. Estimating effectiveness of cardiac arrest interventions: a logistic regression survival model. Circulation 1997;96:3308-13.

4 Medical device safety reports n.d. http://www.mdsr.ecri.org/information/picklists.aspx (accessed 15 Apr 2018).

5 Fairbanks RJ, Wears RL. Hazards with medical devices: the role of design. Ann Emerg Med 2008:52:519-21.

6 Cummins RO, Chesemore K, White RD. Defibrillator failures. Causes of problems and recommendations for improvement. Defibrillator Working Group. JAMA 1990;264:1019-25.

7 Emergnecy Medicine Society of South Africa Practice Guideline EM008: Defibrillation 2009. https://emssa.org.za/documents/em008.pdf (accessed 23 Apr 2018).

8 Link MS, Atkins DL, Passman RS, et al. Part 6: electrical therapies: automated external defibrillators, defibrillation, cardioversion, and pacing: 2010 American Heart Association Guidelines for Cardiopulmonary Resuscitation and Emergency Cardiovascular Care. Circulation 2010;122(Suppl 3):S706-19.

9 Joburg n.d. https://www.joburg.org.za/ (accessed 15 Apr 2018).

10 Harris PA, Taylor R, Thielke R, et al. Research electronic data capture (REDCap)-a metadata-driven methodology and workflow process for providing translational research informatics support. J Biomed Inform 2009;42:377-81.

11 Nolan JP, Soar J, Smith GB, et al. Incidence and outcome of in-hospital cardiac arrest in the United Kingdom National Cardiac Arrest Audit. Resuscitation 2014;85:987-92.

12 Ocen D, Kalungi S, Ejoku J, et al. Prevalence, outcomes and factors associated with adult in hospital cardiac arrests in a low-income country tertiary hospital: a prospective observational study. BMC Emerg Med 2015;15:23

13 Stein C. Out-of-hospital cardiac arrest cases in Johannesburg, South Africa: a first glimpse of short-term outcomes from a paramedic clinical learning database. Emerg Med J 2009:26:670-4. 


\section{Original research}

14 Moitra VK, Einav S, Thies K-C, et al. Cardiac Arrest in the Operating Room. Anesthesia \& Analgesia 2018;126:876-88.

15 Nadkarni VM, Larkin GL, Peberdy MA, et al. First documented rhythm and clinical outcome from in-hospital cardiac arrest among children and adults. JAMA 2006;295:50.

16 Bunch TJ, Hammill SC, White RD. Outcomes after ventricular fibrillation outof-hospital cardiac arrest: expanding the chain of survival. Mayo Clin Proc 2005:80:774-82.

17 Hope WW, von der Embse K, Mostafa G, et al. Cardiopulmonary arrest occurring in the radiology department: patient characteristics, incidence, and outcomes. Am Surg 2011;77:273-6.

18 White RD, Chesemore KF. Charge! FDA recommendations for maintaining defibrillator readiness. JEMS 1992;17:70-82.
19 Louw P, Maritz D, Wallis L. Emergency centres lack defibrillator knowledge. S Afr Med J 2010;100:435-6.

20 Dyson E, Smith GB. Common faults in resuscitation equipment-guidelines for checking equipment and drugs used in adult cardiopulmonary resuscitation. Resuscitation 2002;55:137-49.

21 McNaughton GW, Wyatt JP, Byrne JC. Defibrillation-a burning issue in coronary care units! Scott Med J 1996;41:47-8.

22 Polisena J, Jutai JW, Chreyh R. A proposed framework to improve the safety of medical devices in a Canadian hospital context. Medical Devices: Evidence and Research 2014;7:139-47.

23 Sezdi M. Two Different Maintenance Strategies in the Hospital Environment: Preventive Maintenance for Older Technology Devices and Predictive Maintenance for Newer High-Tech Devices. J Healthc Eng 2016;2016:1-16. 